\title{
Effective Hearing Loss Screening in Primary Care: The Early Auditory Referral-Primary Care Study
}

\author{
Pbilip Zazove, MD, $M M^{1}$ \\ Melissa A. Plegue, $M A^{1}$ \\ Michael M. McKee, MD, MPH \\ Melissa DeJonckbeere, $P b D^{1}$ \\ Paul R. Kileny, $\mathrm{PbD}^{2}$ \\ Lauren S. Scbleicher, $M A^{1}$ \\ Lee A. Green, MD, $M P H^{3}$ \\ Ananda Sen, $\mathrm{PbD}^{4}$ \\ Mary E. Rapai, $M A^{1}$ \\ Elie Mulbem, $M D^{5}$ \\ 'Department of Family Medicine, Univer- \\ sity of Michigan, Ann Arbor, Michigan \\ ${ }^{2}$ Otorhinolaryngology Department, Univer- \\ sity of Michigan, Ann Arbor, Michigan \\ ${ }^{3}$ Department of Family Medicine, Univer- \\ sity of Alberta, Edmonton, Alberta, Canada \\ ${ }^{4}$ Department of Family Medicine \\ and Biostatistics, University of Michigan, \\ Ann Arbor, Michigan \\ ${ }^{5}$ Department of Family Medicine, Oakland \\ University William Beaumont School \\ of Medicine, Rochester, Michigan
}

AC Annals Journal Club selection; see inside back cover or http://www annfammed.org/site/AJC/.

Conflicts of interest: authors report none.

\section{CORRESPONDING AUTHOR}

Philip Zazove, MD, MM

University of Michigan

Department of Family Medicine

1018 Fuller Street

Ann Arbor, MI 48104-1213

pzaz@med.umich.edu

\begin{abstract}
PURPOSE Hearing loss, the second most common disability in the United States, is under-diagnosed and under-treated. Identifying it in early stages could prevent its known substantial adverse outcomes.
\end{abstract}

METHODS A multiple baseline design was implemented to assess a screening paradigm for identifying and referring patients aged $\geq 55$ years with hearing loss at 10 family medicine clinics in 2 health systems. Patients completed a consent form and the Hearing Handicap Inventory for the Elderly (HHI). An electronic alert prompted clinicians to screen for hearing loss during visits.

RESULTS The 14,877 eligible patients during the study period had 36,701 encounters. Referral rates in the family medicine clinics increased from a baseline rate of $3.2 \%$ to $14.4 \%$ in 1 health system and from a baseline rate of $0.7 \%$ to $4.7 \%$ in the other. A general medicine comparison group showed referral rate increase from the $3.0 \%$ baseline rate to $3.3 \%$. Of the 5,883 study patients who completed the HHI $25.2 \%(n=1,484)$ had HHI scores suggestive of hearing loss; those patients had higher referral rates, $28 \%$ vs $9.2 \%(P<.001)$. Of 1,660 patients referred for hearing testing, 717 had audiology data available for analysis: 669 (93.3\%) were rated appropriately referred and 421 (58.7\%) were considered hearing aid candidates. Overall, $71.5 \%$ of patients contacted felt their referral was appropriate.

CONCLUSION An electronic alert used to remind clinicians to ask patients aged $\geq 55$ years about hearing loss significantly increased audiology referrals for atrisk patients. Audiologic and audiogram data support the effectiveness of the prompt. Clinicians should consider adopting this method to identify patients with hearing loss to reduce its known and adverse sequelae.

Ann Fam Med 2020;18:520-527. https://doi.org/10.1370/afm.2590.

\section{INTRODUCTION}

$\mathrm{H}$ earing loss affects over $30 \%$ of those aged $\geq 55$ years, with over one-half suffering morbidity that includes reduced quality of life. ${ }^{1-14}$ Untreated hearing loss is a major risk factor for substantial health conditions (hypertension, diabetes, dementia, depression) $)^{2-4,10,11,15-22}$ as well as increased health care cost and use. ${ }^{23-26}$ Patients with hearing loss are reluctant to reveal it, and most non-otolaryngologist physicians provide inadequate hearing care to these patients. It is a condition physicians often do not suspect, are uncomfortable with, or consider unimportant despite growing recognition of its impact on health. ${ }^{27,28}$ In fact, $75 \%$ of hearing loss remains underdiagnosed and undertreated. ${ }^{27-30}$

Common screening tests can effectively identify patients with hearing loss, ${ }^{15,31-33}$ yet physicians rarely use them. ${ }^{7}$ Primary care physicians, the vanguard for screening and prevention, juggle multiple office demands ranging from treating ill patients to addressing quality metrics ${ }_{i}^{34,35}$ thus implementing new interventions, regardless of importance, is hard. ${ }^{35-38}$ Other barriers to screening are poor understanding of hearing loss, optimal screening, counseling, and referral approaches. 3,6,27,29,30,39 Despite effective treatments being available, there are multiple barriers that reduce the likelihood of screening in the primary care setting. Most patients are reluctant to reveal 
their hearing loss. ${ }^{40-43}$ However, those with established primary care physicians, if asked, will discuss their hearing and often follow treatment recommendations that are known to be effective. ${ }^{27,30,32,39,40,44}$

The US Preventive Services Task Force acknowledges the adverse outcomes from untreated hearing loss. ${ }^{15}$ They state, however, that "adequately powered studies are needed to better evaluate the effect of screening for hearing loss on health outcomes (in older persons)...particularly among adults without self-perceived or established hearing loss at baseline. ${ }^{\prime \prime 15}$ Thus, hearing loss screening is rated "I," ie, "...evidence is insufficient to assess the balance of benefits and harms of screening in asymptomatic adults aged 50 years or older." ${ }^{15}$

The Early Auditory Referral-Primary Care study was designed to address the lack of data about hearing loss screening. ${ }^{15}$ Implemented in real-world, community-based clinics, it evaluated the effect of a tailored electronic alert appearing at all visits of patients aged $\geq 55$, to encourage clinicians to ask the single question screener: "Do you have difficulty with your hearing?" This article summarizes the findings.

\section{METHODS}

University of Michigan and Beaumont Health Institutional Review Boards approved the research.

\section{Study Setting}

The first 2 years of the Early Auditory ReferralPrimary Care study developed and tested a Best Practice Alert (BPA) in Epic (Epic Systems Corporation) to prompt clinicians to ask about hearing loss. ${ }^{44}$ The study's implementation phase, reported here, was conducted from July 2016 through February 2019 at the University of Michigan (UM) and Beaumont Health (BH) family medicine clinics using Epic electronic health records. Patients were enrolled from 5 practices in each system, and all clinicians at the practices (faculty, residents, midlevel clinicians) were included. Audiograms performed on referred patients were obtained when available. All UM referrals went to UM audiologists plus 2 private audiologists. All BH referrals were to private medical offices.

An 11-minute in-person hearing loss educational video was presented to available clinicians at each site 1 week before activating the BPA. It reviewed general hearing loss information, brief information about hearing aids, and suggestions for counseling patients with hearing loss. Approximately 28\% $(n=40)$ of UM and $52 \%(n=33)$ of $\mathrm{BH}$ clinicians viewed the video.

All patients aged $\geq 55$ years seen at study sites during the enrollment period were invited to participate and handed a description of the study plus a consent form. Due to high volumes, this was a self-administered, paper-based consent process. Consenting patients completed a Hearing Handicap Inventory for the Elderly $(\mathrm{HHI})^{31,33}$ our gold standard to identify patients at risk for hearing loss. HHI is a 10 -question patient-completed questionnaire that is a well validated standard screening instrument in primary care ${ }^{31,45,46}$ Clinicians were blinded to $\mathrm{HHI}$ results. Data from patients declining consent to individual level analysis was used in aggregated deidentified form to assess primary outcomes.

\section{Measures}

The hearing loss alert (ie, BPA in Epic) ${ }^{44}$ appeared when clinicians saw eligible patients who did not have hearing loss on their problem list. Five possible responses to the alert existed: (1) the patient had known hearing loss, (2) the patient had suspected hearing loss (responded yes to the single question) and was referred for testing, (3) the patient had suspected hearing loss but declined referral, (4) the patient did not have hearing loss (answered no to the single question), and (5) the clinician did not address the alert. Responses to all alerts were recorded and analyzed.

For our trial, we used a multiple baseline design that is a special case of a stepped wedge trial. The multiple baseline design makes staggered starts that are synchronized with interventions offered at multiple time points, to facilitate causal inference. ${ }^{47}$ This design offers a lower cost alternative with potentially smaller sample sizes compared to traditional designs. ${ }^{48}$

Sites were enrolled in a staggered format, a new site added approximately every 3 to 4 months in each health system. Once a site was enrolled, the alert triggered for every eligible patient seen and prompted the clinician to ask the patient, "Do you have difficulty with your hearing?" If clinicians did not ask about hearing loss, the alert reappeared at future visits for that patient until addressed. Once addressed, it turned off for time-lengths based on the outcome-for patients with known hearing loss it turned off permanently; for those declining testing it turned off for 1 year $r_{i}$ and for those referred, it remained until a hearing specialist saw the patient. The same alert was used at both institutions. A separate process prompted audiologists to answer 3 questions: referral appropriateness, hearing loss severity, and if hearing aid evaluation was recommended ${ }^{44} \mathrm{~A}$ few audiograms collected from private offices without responses to the questions were answered by our audiologist co-investigator (P.K.). We calculated pure tone averages (average of decibel losses at $500 \mathrm{~Hz}, 1,000$ $\mathrm{Hz}, 2,000 \mathrm{~Hz}$, and $4,000 \mathrm{~Hz}$ ) for each ear from each audiogram and categorized them as mild, moderate, or severe using World Health Organization criteria. ${ }^{49}$ 
Demographics, race, ethnicity, insurance, medical diagnoses on the problem list, and frequency of hearing loss on the problem list at baseline were obtained directly from the Epic electronic health records.

Follow-up telephone calls were made to approximately $20 \%$ of study participants, selected at random, who were either referred for hearing loss testing or had a positive $\mathrm{HHI}$ score $(\geq 10)$. Responses to survey questions focusing on patient perceptions about hearing loss, discussions with their physicians, and compliance with any referrals (and why/why not) were collected.

\section{Statistical Analysis}

Participant demographic and comorbidity variables were summarized for all sites within each institution. Distributions between institutions were compared using Pearson's $\chi^{2}$ tests, except for age which was compared using a $t$-test. Percentage of patients referred to audiology with hearing loss diagnosis on the problem list were compared to rates from 1 year immediately prior (baseline) to the study period using Pearson's $\chi^{2}$ tests at each institution. Baseline rates were calculated from aggregate (de-identified) data on all patients seen at participating clinics who met study criteria. Study period rates were calculated using comparable aggregate data-based rates during the intervention period as well as rates from study participants. A Cochran-Mantel-Haenszel test was used to compare the change in referral rates across institutions. ${ }^{50}$ Because the clinics were under the intervention for different lengths of time, we adjusted for months under intervention as a clinic-level covariate in our referral rates analysis. Referral rates of patients with probable hearing loss ( $\mathrm{HHI}$ score $\geq 10$ ) vs those unlikely to have hearing loss $(\mathrm{HHI}<10)$ were compared using Pearson's $\chi^{2}$ tests. Percentages of all referred patients seen by audiology and audiologist evaluations of referral appropriateness were assessed for participants.

Associations between participant demographics (age, sex, race, smoking status, insurance), and comorbidities (obesity, high blood pressure, diabetes) with referral status were examined using a clustered logistic regression under a generalized estimating equations framework. Models were clustered by clinic using an exchangeable correlation structure and a fixed effect for institution was included in the model. An additional model on the subset of individuals who had $\mathrm{HHI}$ information available was fit to explore the likelihood of referral for those who had indications of hearing loss $(\mathrm{HHI} \geq 10)$, adjusting for potential confounders.

\section{RESULTS}

There were $14,411\left(11,151 \mathrm{UM}_{i} 3,260 \mathrm{BH}\right)$ patients arriving at the sites for whom individual level data were obtained. HHI information was available only for the 5,893 study participants $\left(2,641 \mathrm{UM}_{i} 3,252 \mathrm{BH}\right)$.

Eight $\mathrm{BH}$ patients did not have HHI scores. The 11,151 UM patients had 29,361 encounters and the 3,260 BH patients had 7,340 encounters during the study period.

\section{Demographics}

Patient characteristics differed between the 2 institutions (Table 1), though this was clinically significant only for insurance, where UM had significantly more private pay patients. Comorbidity prevalence was similar for both health systems.

\section{Table 1. Demographic and Comorbidity Characteristics of All Participants ${ }^{a, b}$}

\begin{tabular}{|c|c|c|c|}
\hline Characteristic & $\underset{(n=11,151)}{\text { UM }_{(n)}}$ & $\begin{array}{c}\text { BH } \\
(n=3,260)\end{array}$ & $\begin{array}{c}P \\
\text { Value }\end{array}$ \\
\hline Age, mean (SD) & $65.0(8.7)$ & $65.6(8.6)$ & $<.001$ \\
\hline Gender, No. (\%) & & & $<.001$ \\
\hline Female & $6,242(56.0)$ & $2,056(63.1)$ & \\
\hline Male & $4,909(44.0)$ & $1,204(36.9)$ & \\
\hline Race, No. (\%) & & & $<.001$ \\
\hline White & $9,548(85.6)$ & $2,786(85.5)$ & \\
\hline Black & $799(7.2)$ & $271(8.3)$ & \\
\hline Other & $689(6.2)$ & $112(3.4)$ & \\
\hline Unknown & $115(1.0)$ & $91(2.8)$ & \\
\hline Ethnicity, No. (\%) & & & $<.001$ \\
\hline Hispanic & $199(1.8)$ & $16(0.5)$ & \\
\hline Non-Hispanic & $10,413(93.4)$ & 2,931 (89.9) & \\
\hline Unknown & $539(4.8)$ & $313(9.6)$ & \\
\hline Marital status, No. (\%) & & & $<.001$ \\
\hline $\begin{array}{l}\text { Married/significant } \\
\text { other }\end{array}$ & $7,200(64.6)$ & $1,951(59.9)$ & \\
\hline Divorced/separated & $496(4.5)$ & $399(12.2)$ & \\
\hline Other & $3,092(27.7)$ & $905(27.8)$ & \\
\hline Unknown & $363(3.3)$ & $5(0.2)$ & \\
\hline $\begin{array}{l}\text { Smoking status, } \\
\text { No. }(\%)\end{array}$ & & & $<.001$ \\
\hline Yes & $1,189(10.7)$ & $442(13.6)$ & \\
\hline Quit & $4,108(36.8)$ & $1,313(40.3)$ & \\
\hline Never & $5,849(52.5)$ & $1,484(45.5)$ & \\
\hline Unknown & $5(0.04)$ & $21(0.6)$ & \\
\hline Hypertension, No. (\%) & $4,562(40.9)$ & $1,247(38.3)$ & .007 \\
\hline Diabetes, No. (\%) & $1,819(16.3)$ & $489(15.0)$ & .084 \\
\hline Alcohol abuse, No. (\%) & $175(1.6)$ & $98(3.0)$ & $<.001$ \\
\hline Insurance, No. (\%) & & & $<.001$ \\
\hline Private & $6,632(59.5)$ & $1,178(36.1)$ & \\
\hline Medicare/federal & $3,905(35.0)$ & $1,066(32.7)$ & \\
\hline Medicaid & $513(4.6)$ & $190(5.8)$ & \\
\hline Uninsured & $101(0.9)$ & $11(0.3)$ & \\
\hline Unknown & $0(0.0)$ & $815(25.0)$ & \\
\hline
\end{tabular}




\section{Best Practice Alert Response and Referral Rates}

At both institutions, referrals increased significantly vs baseline rates for both consented and all patients (Table 2). Cochran-MantelHaenszel testing was significant $(P=.0004)$ indicating that referral rate changes were different between institutions.

Since Medicare wellness visits (includes hearing loss screening) for persons aged $\geq 65$ years were implemented nationally during the study period, we evaluated UM general medicine sites referral rates. They had non-clinically significant increases in referrals vs baseline $(3.3 \%$ vs $3.0 \%, P=.04)$.

Hearing loss was documented on the problem list for $58(0.5 \%)$ participants at UM, not significantly different from the baseline rate of $0.5 \%(P=.85)$. At BH, $266(8.2 \%)$ participants had hearing loss documented on their problem list, a significant increase from the baseline rate of $2.3 \%(P<.001)$.

\section{Hearing Handicap Inventory Findings}

$\mathrm{HHI}$ data from 5,893 patients $(2,641 \mathrm{UM}, 3,252 \mathrm{BH})$ showed overall $25.2 \%(\mathrm{n}=1,484)$ scores $\geq 10$, suggestive of hearing loss; $29.5 \%(\mathrm{n}=778)$ at UM and $21.7 \%$ at $\mathrm{BH}(\mathrm{n}=706)$. Patients with HHI scores $\geq 10$ vs scores $<10$ had greater overall referral rates, $28 \%$ vs $9.2 \%$ ( $P$ $<.001)$ respectively. HHI scores $\geq 10$ were associated with increased age, male sex, White race, and having diabetes. (Table 3)

A generalized estimating equations model, clustered by clinic, run on all participants, found White patients and patients with diabetes had higher odds of referral while smokers had lower odds of referral (Table 4). For consented patients with $\mathrm{HHI}$ scores, these associations disappeared after adjusting for the presence or absence of $\mathrm{HHI}$ scores $\geq 10$. A strong association between high HHI scores with referral indicated that clinicians were likely to refer patients appropriately based on the single question $(\mathrm{HHI}$ results were blinded to clinicians). Months under intervention had a mildly significant association ( $\mathrm{OR}=0.96 ; 95 \% \mathrm{CI}, 0.93-0.99)$ but the direction was counter-intuitive, with greater time under observation associated with a lower referral rate. When the results were compared to a model without time as a covariate, the findings between these models were virtually identical.

\section{Best Practice Alert Encounter Data}

The alert was addressed for 10,567 of all 14,877 eligible patients. There was an average of $1.7(\mathrm{SD}=1.4)$ encounters before the alert was first responded to, $14 \%$ of which resulted in a referral. The alert was not addressed at any encounter for $3,812(26.5 \%)$ patients (UM - 32.4\% vs BH - $6.3 \% ; P<.001$ ). Patients who never had the alert addressed averaged 2.6 encounters $(\mathrm{SD}=2.1)$ in which the alert prompted the physician.

\section{Audiologic Data}

Of 1,660 patients referred for hearing testing, 717 $(43.2 \%)$ were seen and had data available. Audiologists deemed 669 referrals $(93.3 \%)$ appropriate, $6(0.8 \%)$ not appropriate, and 42 (5.9\%) were not rated. Asymmetric hearing loss was present in $228(31.8 \%)$ patients, and $421(58.7 \%)$ patients were considered hearing aid candidates. Of the 717 audiograms, 540 were available to be coded using the World Health Organization criteria for pure tone average (PTA) calculations (average of decibel $[\mathrm{dB}]$ losses at 4 frequencies: $500 \mathrm{~Hz}, 1,000 \mathrm{~Hz}$, 2,000 $\mathrm{Hz}$ and $4,000 \mathrm{~Hz})^{49}$ (Table 5).

There were 284 patients with both audiograms and $\mathrm{HHI}$ ratings available, split evenly between $\mathrm{HHI}$ scores $\geq 10$ and $<10$. HHI score was associated with PTA dB loss. In the better ear, mean PTA loss was $27.5 \mathrm{~dB}$ (SD 11.9) for $\mathrm{HHI} \geq 10$ vs $19.6 \mathrm{~dB}$ (SD 9.3) for $\mathrm{HHI}<10(P$

Table 3. Characteristics of Participants With Low vs High HHI Scores

\begin{tabular}{lcrr}
\hline Characteristic & $\begin{array}{c}\text { HHI <10 } \\
(\mathbf{n = 4 , 4 0 9 )}\end{array}$ & $\begin{array}{c}\text { HHI } \geq 10 \\
(\mathbf{n = 1 , 4 8 4 )}\end{array}$ & $\begin{array}{c}\boldsymbol{P} \\
\text { Value }\end{array}$ \\
\hline Age, mean (SD) & $64.8(7.9)$ & $65.6(8.5)$ & $<.001$ \\
Male, No. (\%) & $1,604(36.4)$ & $717(48.3)$ & $<.001$ \\
White, No. (\%) & $3,811(88.2)$ & $1,328(91.1)$ & .002 \\
High blood pressure, & $1,680(38.1)$ & $607(40.9)$ & .056 \\
$\quad$ No. (\%) & & & \\
$\begin{array}{l}\text { Diabetic, No. (\%) } \\
\text { Smoker, No. (\%) }\end{array}$ & $664(15.1)$ & $269(18.1)$ & .005 \\
$\begin{array}{l}\text { Referred to audiol- } \\
\text { ogy, No. (\%) }\end{array}$ & $401(9.1)$ & $415(28.0)$ & $<.001$ \\
\hline HHI = hearing handicap inventory. & & \\
\hline
\end{tabular}


$<.001)$. In the worse ear mean PTA loss was $33.6 \mathrm{~dB}$ (SD 15.2) for $\mathrm{HHI} \geq 10$ ( $P<.001)$ vs $23.1 \mathrm{~dB}$ (SD 10.3) for $\mathrm{HHI}<10$. Speech reception threshold (SRT) scores were also associated with $\mathrm{HHI}$ scores: for HHI scores $\geq 10$ vs $<10$, in the better ear mean SRT (SD) was 23.3 (11.2) dB loss vs $17.3(7.7) \mathrm{dB}$ loss, respectively $(P$ $<.001)$, and in the worse ear mean SRT (SD) was 27.6 (14.8) dB vs $19.3(9.0) \mathrm{dB},(P<.001)$. Word recognition data was highly skewed; $55 \%$ of all participants had scores of $100 \%$, and $82 \%$ had scores $>90 \%$, making analysis difficult.

\section{Telephone Call Data}

Of 557 consented patients who had 3-month followup telephone calls, $392(70.4 \%)$ recalled discussing hearing loss with their clinician; 347 (62.3\%) recalled being referred for hearing testing of whom $314(56.4 \%)$ accepted the referral and 33 (5.9\%) did not. Over onehalf were glad the conversation occurred.

Among those recalling a referral, most (61\%) were glad they received it, and when asked if it was appropriate, $71.5 \%$ said yes, $7 \%$ said no, and the remainder were unsure or had no opinion. For those accepting a referral, $85 \%$ made an appointment and 70\% (219) had the testing. Of the 219 individuals tested, $60 \%$ said a recommendation was made, most commonly hearing aids $(64 \%) ; 71 \%$ of those receiving recommendations found them appropriate and 70\% planned to follow them. If hearing aids were recommended, one-half planned to get them; the most common reason for not doing so was cost.

Table 4. Factors Associated With Referral to Audiology (GEE Model Results)

\begin{tabular}{|c|c|c|c|c|}
\hline \multirow[b]{2}{*}{ Characteristic } & \multicolumn{2}{|c|}{$\begin{array}{l}\text { Full Sample } \\
(n=13,381)\end{array}$} & \multicolumn{2}{|c|}{$\begin{array}{l}\text { Sample With HHI } \\
(n=4,964)\end{array}$} \\
\hline & OR $(95 \% \mathrm{Cl})$ & $P$ Value & OR $(95 \% \mathrm{CI})$ & $P$ Value \\
\hline Age & $0.99(0.98-1.02)$ & .95 & $1.00(0.99-1.01)$ & .98 \\
\hline Male & $1.05(0.94-1.16)$ & .40 & $0.99(0.87-1.14)$ & .98 \\
\hline White & 1.27 (1.17-1.39) & $<.001$ & $1.01(0.82-1.24)$ & .93 \\
\hline High blood pressure & $1.06(0.99-1.14)$ & .10 & $0.97(0.89-1.05)$ & .44 \\
\hline Diabetic & $1.17(1.04-1.32)$ & .007 & $1.18(0.97-1.43)$ & .10 \\
\hline Smoker & $0.84(0.74-0.94)$ & .003 & $1.14(0.86-1.51)$ & .37 \\
\hline \multicolumn{5}{|l|}{ Insurance } \\
\hline Private & Reference & & Reference & \\
\hline Medicare/federal & $1.12(0.96-1.31)$ & .13 & $1.12(0.99-1.27)$ & .09 \\
\hline Medicaid & $1.11(0.83-1.48)$ & .46 & $0.94(0.55-1.60)$ & .81 \\
\hline Uninsured & $0.68(0.36-1.29)$ & .22 & $1.23(0.41-3.73)$ & .71 \\
\hline Institution (Ref = BH) & $2.58(1.65-4.02)$ & $<.001$ & $4.71(2.89-7.68)$ & $<.001$ \\
\hline $\begin{array}{l}\text { Clinic intervention } \\
\text { time (Months) }\end{array}$ & $0.96(0.93-0.99)$ & .03 & $0.94(0.90-0.99)$ & .04 \\
\hline $\mathrm{HHI} \geq 10$ & $\ldots$ & $\ldots$ & $3.67(3.19-4.21)$ & $<.001$ \\
\hline
\end{tabular}

\section{DISCUSSION}

Our intervention, focused on getting clinicians to ask "Do you have difficulty with your hearing?" and tested in 2 family medicine health systems serving diverse patients, significantly increased identification and referral of patients at risk for hearing loss. Referrals of these patients increased almost fivefold (from 2.2\% to $10.7 \%$ ) vs minimal increases (3.0 to $3.3 \%$ ) in the general medicine comparison group. The increased referral rate was sustained over the 2-3 years of the study as patients were referred at subsequent alert prompts, suggesting the intervention will be increasingly effective over time. Also, $28 \%$ of patients with positive HHI scores (blinded to clinicians) were referred based on the screening question vs only $9.2 \%$ of those with negative $\mathrm{HHI}$ scores were referred. This supports the audiologist assessments that $93 \%$ of the referrals seen were appropriate. The $72 \%$ of participants with a positive $\mathrm{HHI}$ who were not referred is likely due to a combination of patients not admitting their hearing loss, clinicians too busy to address the alert, and patients declining referrals. Of note, our population hearing loss rates (using $\mathrm{HHI}$ data) were similar to other studies $^{51-53}$ suggesting that our outcomes are applicable to typical community populations.

Audiologists stated $85 \%$ of referred patients had hearing loss, most of them mild. Mild hearing loss can negatively impact income, ${ }^{51}$ cognitive function, ${ }^{2,4,54}$ physical health, ${ }^{55}$ quality of life, ${ }^{2,4,9}$ depression, ${ }^{2,6}$ and social interaction, ${ }^{8,9}$ while increasing dependence on social support systems ${ }_{1}^{14}$ communication difficulties, hospital admissions, ${ }^{26}$ and readmission rates. ${ }^{23-25}$ Our average PTA findings $(25 \mathrm{~dB}$ loss in the better ear and $30.7 \mathrm{~dB}$ loss in the worse ear) confirmed that hearing loss was identified at an early stage. This increases the chances that treatment (hearing aids, etc) could reduce sequelae. That is particularly true since the impact of mild hearing loss is greater in noisy real-world settings than the quiet testing environments where our PTA numbers were obtained. It should be emphasized that a $6 \mathrm{~dB}$ decrease in the PTA is equal to a doubling of the hearing loss impact in life. ${ }^{56}$

Electronic health record alerts are often difficult to use, reducing their effectiveness. ${ }^{57}$ The Early Auditory Referral-Primary Care alert had been extensively vetted and approved by physicians and configured to support efficient cognitive processing. ${ }^{57}$ 


\begin{tabular}{|c|c|}
\hline Findings & Values \\
\hline \multicolumn{2}{|l|}{ Pure tone average, $\mathrm{dB}$ loss } \\
\hline Better ear, mean (SD) & $25.0(11.9)$ \\
\hline Worse ear, mean (SD) & $30.7(14.5)$ \\
\hline \multicolumn{2}{|c|}{ Speech reception threshold, dB loss $(n=537)$} \\
\hline Better ear, mean (SD) & $21.3(10.3)$ \\
\hline Worse ear, mean (SD) & $25.2(13.6)$ \\
\hline \multicolumn{2}{|l|}{ Word recognition $(n=538)$} \\
\hline Better ear, \% correct mean (SD) & $96.8(6.3)$ \\
\hline Worse ear, \% correct mean (SD) & $94.1(12.1)$ \\
\hline Hearing aid candidate, No. (\%) & $353(65.4)$ \\
\hline \multicolumn{2}{|c|}{ Classification of HL (based on better ear), No. (\%) ${ }^{\mathrm{a}}$} \\
\hline No loss & $306(56.7)$ \\
\hline Slight/mild & $172(31.9)$ \\
\hline Moderate & $57(10.6)$ \\
\hline Severe & $5(0.9)$ \\
\hline \multicolumn{2}{|c|}{ Classification of HL (based on worse ear), No. (\%)a } \\
\hline No loss & $229(42.4)$ \\
\hline Slight/mild & $185(34.3)$ \\
\hline Moderate & $103(19.1)$ \\
\hline Severe & $21(3.9)$ \\
\hline Profound & $2(0.4)$ \\
\hline \multicolumn{2}{|l|}{$\mathrm{dB}=$ decibel $; \mathrm{HL}=$ hearing loss. } \\
\hline a Based on WHO criteria. ${ }^{49}$ & \\
\hline
\end{tabular}

Still, our most common alert response remained "not addressed." We believe this is both due to lack of clinician time and the mental model clinicians have about hearing loss. In short, they are uncomfortable addressing hearing loss as discussed elsewhere. ${ }^{57}$ Physicians have little training regarding care for hearing loss, are largely unaware of its sequelae, and are uncomfortable discussing hearing care interventions. Potential interventions include improved clinician education, or greater use of other medical personnel (nurses, aides, etc) to address the alert. Moreover, our finding that cost is the most common reason for patients declining hearing aids is consistent with other studies, which also show that vanity and negative connotations of hearing aids are 2 other frequent reasons for lack of use. ${ }^{58}$ Increasing hearing aid use will require reducing the cost of aids (whether via Medicare coverage or less expensive versions).

Although this study was not a comparison between the 2 institutions, UM had greater referral rates for hearing testing, audiology seeing referred patients, and "not-addressed" alerts. The greater UM referral rates may be due to their 2 deaf family physicians raising the level of awareness for all clinicians. Additionally, UM's Department of Family Medicine has an emphasis on improving care for patients with disabilities which may have increased referral rates. The increased audiology visits may be due to the fact that UM has all clinicians in 1 system; patients know their insurance is accepted, and audiologist have full access to patient information. Moreover, the cost to see an audiologist is less than an otolaryngologist (where Beaumont patients were referred), though we did not verify if that caused fewer hearing evaluation visits. The recent over-the-counter hearing aid act ${ }^{59}$ of 2017 may result in many patients trying over-the-counter hearing aids vs getting official hearing testing.

$\mathrm{BH}$ had few best practice alerts during the study period $_{i}$ thus, its clinicians had less familiarity with alerts, potentially reducing their comfort using them to refer patients. Still, BH sites increased their referrals for hearing loss testing 7 -fold, supporting the intervention's effectiveness. Regarding the greater "not addressed" UM alert rate, this may reflect alert fatigue because UM sites have $>50$ alerts, which aggravates time constraints in busy practices. Future research is needed to understand physician/staff perspectives that influence intervention effectiveness.

\section{Limitations}

Our study was conducted with family physicians and their advanced practice providers, who may have different receptivity than other primary care physicians and advanced practice providers for hearing loss interventions, alerts, and workflow changes. Our alert was uniquely designed, and the outcomes may not apply to other alerts. Study patients were predominantly middle-class, White, and aged $\geq 55$ years; findings may not apply to other populations though we did not see a difference in referral rates between race, ethnicity, or age. It is possible that patients concerned about a hearing loss were more likely to consent to the study. The fact that the consented population hearing loss rates (using HHI data) were similar to other studies, and that the aggregate data (all patients seen in the clinics, not just consented patients) showed similar referral rates suggests this was not the case.

Our findings demonstrate that using an electronic alert to prompt primary care clinicians to ask the single question, "Do you have difficulty with your hearing?" to identify and refer appropriate at-risk patients for hearing testing is feasible and improves outcomes. This should increase the chances that hearing loss patients, who suffer substantial morbidity when untreated, will get better and earlier hearing health care with potentially fewer hospitalizations and improved quality of life.

To read or post commentaries in response to this article, see it online at https://www.AnnFamMed.org/content/18/6/520.

Key words: audiology; family practice; family medicine; hearing loss; mass screening; primary care 
Submitted, January 14, 2020; submitted, revised, May 4, 2020; accepted, May 11, 2020.

Funding support: This study was supported by NIDCD grant 4-R33-DC-013678-03

\section{References}

1. Zazove P, Meador HE, Reed BD, Sen A, Gorenflo DW. Cancer prevention knowledge of people with profound hearing loss. J Gen Intern Med. 2009;24(3):320-326.

2. Wallhagen MI, Strawbridge WJ, Shema SJ. The relationship between hearing impairment and cognitive function: a 5-year longitudinal study. Res Gerontol Nurs. 2008;1(2):80-86.

3. National Council on the Aging. The consequences of untreated hearing loss in older persons. ORL Head Neck Nurs. 2000;18(1):12-16.

4. Hogan A, O'Loughlin K, Miller P, Kendig H. The health impact of a hearing disability on older people in Australia. J Aging Health. 2009;21(8):1098-1111.

5. Solheim J, Kværner KJ, Falkenberg ES. Daily life consequences of hearing loss in the elderly. Disabil Rehabil. 2011;33(23-24): 2179-2185.

6. Campbell VA, Crews JE, Moriarty DG, Zack MM, Blackman DK. Surveillance for sensory impairment, activity limitation, and healthrelated quality of life among older adults-United States, 19931997. MMWR CDC Surveill Summ. 1999;48(8):131-156.

7. Mulrow CD, Tuley MR, Aguilar C. Sustained benefits of hearing aids. J Speech Hear Res. 1992;35(6):1402-1405.

8. Huang Q, Tang J. Age-related hearing loss or presbycusis. Eur Arch Otorhinolaryngol. 2010;267(8):1179-1191.

9. Gopinath B, Schneider J, McMahon CM, Teber E, Leeder SR, Mitchell P. Severity of age-related hearing loss is associated with impaired activities of daily living. Age Ageing. 2012;41(2):195-200.

10. Mulrow CD, Aguilar C, Endicott JE, et al. Quality-of-life changes and hearing impairment. A randomized trial. Ann Intern Med. 1990; 113(3):188-194.

11. Laforge RG, Spector WD, Stemberg J. The relationship of vision and hearing impairment to one-year mortality and functional decline. J Aging Health. 1992;4(1):126-148.

12. Johnson CE, Newman CW, Danhauer JL, Williams VA. Eye on the elderly. Screening for hearing loss, risk of falls: a hassle-free approach. J Fam Pract. 2009;58(9):471-477.

13. Kramer SE, Kapteyn TS, Kuik DJ, Deeg DJ. The association of hearing impairment and chronic diseases with psychosocial health status in older age. J Aging Health. 2002;14(1):122-137.

14. Schneider J, Gopinath B, Karpa MJ, et al. Hearing loss impacts on the use of community and informal supports. Age Ageing. 2010; 39(4):458-464.

15. Chou R, Dana T, Bougatsos C, Fleming C, Beil T. Screening adults aged 50 years or older for hearing loss: a review of the evidence for the U.S. preventive services task force. Ann Intern Med. 2011; 154(5):347-355.

16. Braffett BH, Lorenzi GM, Cowie CC, et al.; DCCT/EDIC Research Group. Risk factors for hearing impairment in Type 1 Diabetes. Endocr Pract. 2019;25(12):1243-1254.

17. Akinpelu OV, Ibrahim F, Waissbluth S, Daniel SJ. Histopathologic changes in the cochlea associated with diabetes mellitus - a review. Otol Neurotol. 2014;35(5):764-774.

18. Helzner EP, Contrera KJ. Type 2 Diabetes and hearing impairment. Curr Diab Rep. 2016;16(1):3.

19. Liu CM, Lee CT. Association of hearing loss with dementia. JAMA Netw Open. 2019;2(7):e198112.

20. Davies HR, Cadar D, Herbert A, Orrell M, Steptoe A. Hearing impairment and incident dementia: Findings from the English Longitudinal Study of Ageing. J Am Geriatr Soc. 2017;65(9):2074-2081.
21. Meneses-Barriviera CL, Bazoni JA, Doi MY, Marchiori LLM. Probable association of hearing loss, hypertension and diabetes mellitus in the elderly. Int Arch Otorhinolaryngol. 2018;22(4):337-341.

22. Agarwal S, Mishra A, Jagade M, Kasbekar V, Nagle SK. Effects of hypertension on hearing. Indian J Otolaryngol Head Neck Surg. 2013; 65(Suppl 3):614-618.

23. Reed NS, Altan A, Deal JA, et al. Trends in health care costs and utilization associated with untreated hearing loss over 10 years. JAMA Otolaryngol Head Neck Surg. 2019;145(1):27-34.

24. Stone J, Hoffman GJ. Congressional research service: Medical hospital readmissions: issues, policy options and PPACA. https://www. hhnmag.com/ext/resources/inc-hhn/pdfs/resources/opencrs-R40 972_20100921.pdf. Published 2010. Accessed Dec 12, 2019.

25. Chang JE, Weinstein B, Chodosh J, Blustein J. Hospital readmission risk for patients with self-reported hearing loss and communication trouble. J Am Geriatr Soc. 2018;66(11):2227-2228.

26. Mahmoudi E, Zazove P, Meade M, McKee MM. Association between hearing aid use and health care use and cost among older adults with hearing loss. JAMA Otolaryngol Head Neck Surg. 2018;144(6): 498-505.

27. Wallhagen MI, Pettengill E. Hearing impairment: significant but underassessed in primary care settings. J Gerontol Nurs. 2008; 34(2):36-42.

28. Cohen SM, Labadie RF, Haynes DS. Primary care approach to hearing loss: the hidden disability. Ear Nose Throat J. 2005;84(1):26, 29-31, 44.

29. Newman CW, Sandridge SA. Hearing loss is often undiscovered, but screening is easy. Cleve Clin J Med. 2004;71(3):225-232.

30. Bogardus ST Jr, Yueh B, Shekelle PG. Screening and management of adult hearing loss in primary care: clinical applications. JAMA. 2003;289(15):1986-1990.

31. Newman CW, Weinstein BE, Jacobson GP, Hug GA. The Hearing Handicap Inventory for Adults: psychometric adequacy and audiometric correlates. Ear Hear. 1990;11(6):430-433.

32. Yueh B, Shapiro N, MacLean CH, Shekelle PG. Screening and management of adult hearing loss in primary care: scientific review. JAMA. 2003;289(15):1976-1985.

33. Hearing Handicap Inventory Questionnaire for Adults, adapted from: Ventry I, Weinstein B. "Identification of elderly people with hearing problems" American Speech-Language-Hearing Association. 1983, 25, 37-42, San Francisco Otolaryngology - Patient Self Assessment Questionnaire. https://www.sfotomed.com. Accessed Jun 7, 2018.

34. Doerr E, Galpin K, Jones-Taylor C, et al. Between-visit workload in primary care. J Gen Intern Med. 2010;25(12):1289-1292.

35. Katerndahl $D$, Wood $R$, Jaén CR. Family medicine outpatient encounters are more complex than those of cardiology and psychiatry. J Am Board Fam Med. 2011;24(1):6-15.

36. Ellis B. Complexity in practice: understanding primary care as a complex adaptive system. Inform Prim Care. 2010;18(2):135-140.

37. Maciosek MV, Coffield AB, Edwards NM, Flottemesch TJ, Goodman MJ, Solberg LI. Priorities among effective clinical preventive services: results of a systematic review and analysis. Am J Prev Med. 2006;31(1):52-61.

38. Nutting PA, Baier M, Werner JJ, Cutter G, Conry C, Stewart L. Competing demands in the office visit: what influences mammography recommendations? J Am Board Fam Pract. 2001;14(5):352-361.

39. Kochkin S. MarkeTrak III: The billion dollar opportunity in the hearing instrument market. Hear J. 1993;46(10):35-39.

40. Wallhagen MI. The stigma of hearing loss. Gerontologist. 2010; 50(1):66-75.

41. Carmen R. Hearing Loss and Hearing Aids: A Bridge to Healing. 2nd ed. Sedona, AZ: Auricle Ink; 2004.

42. Johnson CE, Danhauer JL, Gavin RB, Karns SR, Reith AC, Lopez IP. The "hearing aid effect" 2005: a rigorous test of the visibility of new hearing aid styles. Am J Audiol. 2005;14(2):169-175. 
43. Simmons M. Hearing Loss: From Stigma to Strategy. London, UK: Peter Owen; 2005.

44. Zazove P, Plegue MA, Kileny PR, et al. Initial results of the Early Auditory Referral-Primary Care (EAR-PC) study. Am J Prev Med. 2017;53(4):e139-e146.

45. Ventry IM, Weinstein BE. The hearing handicap inventory for the elderly: a new tool. Ear Hear. 1982;3(3):128-134.

46. U.S. Preventive Services Task Force. Hearing loss in older adults: screening. www.uspreventiveservicestaskforce.org/uspstf/ recommendation/hearing-loss-in-older-adults-screening\#full recommendationstart. Accessed Apr 27, 2020.

47. Rhoda DA, Murray DM, Andridge RR, Pennell ML, Hade EM. Studies with staggered starts: multiple baseline designs and grouprandomized trials. Am J Public Health. 2011;101(11):2164-2169.

48. Hawkins NG, Sanson-Fisher RW, Shakeshaft A, D'Este C, Green LW. The multiple baseline design for evaluating population-based research. Am J Prev Med. 2007;33(2):162-168.

49. Humes LE. The World Health Organization's hearing-impairment grading system: an evaluation for unaided communication in agerelated hearing loss. Int J Audiol. 2019;58(1):12-20.

50. Agresti A. Categorical Data Analysis. Hoboken, New Jersey: John Wiley \& Sons; 2013.

51. Agrawal Y, Platz EA, Niparko JK. Prevalence of hearing loss and differences by demographic characteristics among US adults: data from the National Health and Nutrition Examination Survey, 1999. 2004. Arch Intern Med. 2008;168(14):1522-1530.
52. Cruickshanks KJ, Wiley TL, Tweed TS, et al.; The Epidemiology of Hearing Loss Study. Prevalence of hearing loss in older adults in Beaver Dam, Wisconsin. Am J Epidemiol. 1998;148(9):879-886.

53. Lin FR, Niparko JK, Ferrucci L. Hearing loss prevalence in the United States. Arch Intern Med. 2011;171(20):1851-1852.

54. Lin FR, Albert M. Hearing loss and dementia - who is listening? Aging Ment Health. 2014;18(6):671-673.

55. McKee MM, Stransky ML, Reichard A. Hearing loss and associated medical conditions among individuals 65 years and older. Disabil Health J. 2018;11(1):122-125.

56. Kileny P, Zwolan T. Disgnostic and rehabilitative audiology. In: Cummings Otolaryngology, Head and Neck Surgey. Fifth ed. Elsevier; 2008:1887-1903.

57. Zazove $\mathrm{P}, \mathrm{McKee} M$, Schleicher $\mathrm{L}$, et al. To act or not to act: responses to electronic health record prompts by family medicine clinicians. J Am Med Inform Assoc. 2017;24(2):275-280.

58. McCormack A, Fortnum H. Why do people fitted with hearing aids not wear them? Int J Audiol. 2013;52(5):360-368.

59. Congress.Gov. S.670 - Over-the-Counter Hearing Aid Act of 2017. https://www.congress.gov/bill/115th-congress/senate-bill/670. Accessed Apr 27, 2020 